\title{
Novel ferromagnetic nanoparticle composited PACls and their coagulation characteristics
}

\author{
M. Zhang, F. Xiao, X.Z. Xu, D.S. Wang* \\ State Key Laboratory of Environmental Aquatic Chemistry, Research Center for Eco-Environmental Sciences, CAS, POB 2871, \\ Beijing 100085, China
}

\section{A R T I C L E I N F O}

Article history:

Received 14 February 2011

Received in revised form

9 September 2011

Accepted 16 October 2011

Available online 25 October 2011

\section{Keywords:}

Magnetic composited PACl

Magnetic coagulation

Ferromagnetic nanoparticles

Coagulation characteristics

Floc property

\begin{abstract}
A B S T R A C T
Effects of magnetic nanoparticles on inorganic coagulants and their coagulation performances were studied in the present work. The $\mathrm{Fe}_{3} \mathrm{O}_{4}-\mathrm{SiO}_{2}$ core-shell particle (FSCSP) and superfine iron (SI), were compounded with polyaluminium chloride of basicity 2.0 ( $\mathrm{PACl} 2.0$ ), providing magnetic PACl2.0s (MPACl2.0s). The physiochemical properties of ferromagnetic nanoparticles were investigated using transmission electron microscopy (TEM), the BET method and a zeta potentiometric analyzer. The Al species distributions of the MPACl2.0s and PACl2.0 were examined by liquid ${ }^{27} \mathrm{Al} \mathrm{NMR}$. Jar tests were employed to evaluate the coagulation performances. Floc properties were assessed by use of the electromotive microscope (EM) and small angle laser light scattering (SALLS). The results showed that modified layers of nanoparticles mitigated agglomeration. FSCSP had a larger specific area and pore volume than SI. The addition of ferromagnetic nanoparticles obviously increased the content of $\mathrm{Al}_{\text {un }}$. MPACl2.0s performed better than PACl2.0 in turbidity removal and DOC removal when dosed less than $0.06 \mathrm{mmol} / \mathrm{L}$ as Al. Generally, PACl2.0 + FSCSP (50 mg/L) performed best. Large, loose and weak flocs were produced by MPACl2.0s, which were preferred for the magnetic powder recycling. A plausible structure, Al species-nanoparticles cluster, contributing to the unique properties of MPACl2.0 flocs, was proposed.
\end{abstract}

(c) 2011 Elsevier Ltd. All rights reserved.

\section{Introduction}

Magnetic coagulation, the combination of magnetic matericals and coagulants, has been tested for its effectiveness. The presence of ferromagnetic materials and magnetic fields makes magnetic collection and separation possible, leading to higher efficiency, larger handling capacity, easier manipulation and comparatively lower energy consumption (Ambashta and Sillanpää, 2010). Hence, investigations have been mainly focused on several aspects as follows: (I) Seeding of magnetic particles in the treating water to produce magnetic flocs that can be rapidaly collected in a magnetic separator ( $\mathrm{Li}$ et al., 2010); (II) Integration of magnetic ion exchange $\left(\right.$ MIEX $^{\circledR}$ ) hybrid systems (Singer and Bilyk, 2002) to improve treatment efficiency (Zhang et al., 2007; Korbutowicz et al., 2008); (III) Development and improvement of the magnetic separation system/instrument (Svoboda and Fujita, 2003); (IV) Development of magnetic coagulants by compounding magnetic materials with traditional coagulants.

Although magnetic seeding coagulation and MIEX ${ }^{\circledR}$ resin adsorption can greatly improve removal efficiency, the expense of the magnetic powder and MIEX $^{\circledR}$ resin have restricted their practical application. Nanosorbents, nanocatalysts and so on have been evaluated (Savage and Diallo, 2005). In aqueous systems, iron oxide particles are hydrated, and $\mathrm{Fe}-\mathrm{OH}$ groups can completely cover their surface.

\footnotetext{
* Corresponding author. Tel./fax: +861062849138.

E-mail addresses: freda1102@163.com (M. Zhang), fengxiao@rcees.ac.cn (F. Xiao), easternwind@163.com (X.Z. Xu), wgds@rcees.ac.cn (D.S. Wang).

0043-1354/\$ - see front matter @ 2011 Elsevier Ltd. All rights reserved.

doi:10.1016/j.watres.2011.10.025
} 
Hydrous iron oxides have an amphoteric character. The $\mathrm{Fe}-\mathrm{OH}$ sites on the surface can react with $\mathrm{H}^{+}$or $\mathrm{OH}^{-}$ions from dissolved acids or bases. A positive $\left(\mathrm{Fe}-\mathrm{OH}^{2+}\right)$ or negative $\left(\mathrm{Fe}-\mathrm{O}^{-}\right)$charges can be formed on the surface by protolytic reactions depending on the $\mathrm{pH}$ of the electrolyte solution (Illés and Tombácz, 2006). Magnetic nanoparticles exhibit a finitesize effect and/or high surface-to-volume ratio, resulting in a higher adsorption capacity. Additionally, the magnetic flocculants can be recovered by an external magnetic field.

Therefore, there is high interest in the application of magnetic nanomaterials to water treatment (Shen et al., 2009). Composite magnetic coagulants are considered to have advantages over traditional coagulants since their magnetic components may optimize coagulation behaviors and facilitate the magnetic separation following the coagulation process. Jiang et al. (2010) successfully synthesized magnetic polyferric chloride (MPFC) by combining $\mathrm{Fe}_{3} \mathrm{O}_{4}$ nanoparticles with PFC. The MPFC, a physical mixture, gave a synergistic improvement in Microcystis aeruginosa removal efficiency compared to only PFC. Coagulated flocs showed a higher settling velocity by wrapping up $\mathrm{Fe}_{3} \mathrm{O}_{4}$. Liu et al. (2006) developed a special flocculant to control freshwater cyanobacterial blooms. In their study, hydrochloride acid was firstly mixed with flyash in a proper ratio for modification, and the mixture and the magnetic powder were then put into the algae contaminated water; the aquatic hazardous substances (algal toxins) were thereby effectively adsorbed and removed.

Polyaluminum chloride (PACl) has been widely used and claimed to be superior to other traditional coagulants since it had the advantages of less alkalinity consumption and wider temperature and pH tolerance (Odegaard et al., 1990; Van Benschoten and Edzwald, 1990). The hydrolysis products of $\mathrm{PACl}$ comprise a series of $\mathrm{Al}$ species, especially $\mathrm{Al}_{13}$ polycation, $\left[\mathrm{AlO}_{4} \mathrm{Al}_{12}(\mathrm{OH})_{24}\left(\mathrm{H}_{2} \mathrm{O}\right)_{12}\right]^{7+}$, which has been widely accepted as the critical species in particle aggregation by strong charge neutralization (Johansson, 1960). In addition, PACl can be temporarily refractory to hydrolysis before adsorption onto particle surfaces (Hu et al., 2006). Thus, combining ferromagnetic nanoparticles with $\mathrm{PACl}$ should produce favorable results. However, almost no research has addressed this to date, especially the magnetic coagulation mechanism and the characterizations of the formed flocs.

In the present work, ferromagnetic nanoparticles were mixed with PACl2.0 to develop a novel composite magnetic coagulant MAPCl2.0. The developed coagulant was characterized in terms of $\mathrm{Al}$ species distributions by a liquid ${ }^{27} \mathrm{Al}$ NMR method. In addition, jar tests were conducted to evaluate the MPACl2.0's performance by examining turbidity and DOC removal. The formation, breakage and regrowth of MPACl2.0 flocs were subsequently investigated. Finally, a model was proposed to elucidate the coagulation mechanisms of MPACl2.0s with special emphasis on the role of the ferromagnetic nanoparticles.

\section{Material and methods}

\subsection{Chemicals}

$\mathrm{FeCl}_{3} \cdot 6 \mathrm{H}_{2} \mathrm{O}, \mathrm{FeCl}_{2} \cdot 4 \mathrm{H}_{2} \mathrm{O}, \mathrm{NaHCO}_{3}$, tetraethyl orthosilicate (TEOS) and absolute ethanol were obtained from the
National Medicines Corporation Ltd. of China. $\mathrm{NH}_{3} \cdot \mathrm{H}_{2} \mathrm{O}$, $\mathrm{NaOH}$ and hydrochloric acid were provided by Beijing Chemical Plant. $\mathrm{AlCl}_{3} \cdot 6 \mathrm{H}_{2} \mathrm{O}, \mathrm{NaNO}_{3}$ and Kaolin were obtained from the Xilong Chemical Corporation Ltd. of Shantou, the Jinke Fine Chemical Institute of Tianjin, and the Dongxu Chemical Plant of Beijing, China, respectively. Humic acid was produced by Sigma-Aldrich Corporation Ltd. of USA.

All reagents were of analytical grade without further purification except for being specified, and deionized water was used in preparing all solutions.

\subsection{Preparation of the ferromagnetic nanoparticles}

$\mathrm{Fe}_{3} \mathrm{O}_{4}-\mathrm{SiO}_{2}$ core-shell particles (FSCSP) were prepared in the laboratory. Firstly, $\mathrm{Fe}_{3} \mathrm{O}_{4}$ particles were synthesized by coprecipitation (Hong et al., 2009): $\mathrm{FeCl}_{3}$ and $\mathrm{FeCl}_{2}$ with a molar ratio of 1.7 were prepared in an $\mathrm{N}_{2}$ atmosphere. Excess ammonia aqueous solution was then quickly added into the $\mathrm{Fe}^{3+} / \mathrm{Fe}^{2+}$ solution with vigorous stirring until no precipitates could be seen in the solution, and then another 1 h's stirring was conducted. Finally, precipitates were collected and washed for several times with deionized water and ethanol until the $\mathrm{pH}$ value decreased to 7. $\mathrm{A} \mathrm{SiO}_{2}$ layer was built up by directly introducing $\mathrm{Fe}_{3} \mathrm{O}_{4}$ particles into the primary silica particles by the Stöber process (Lu et al., 2008): a certain amount of ethanol, deionized water, aqueous ammonia and TEOS were added in a three neck flask in a $40{ }^{\circ} \mathrm{C}$ water bath. $\mathrm{Fe}_{3} \mathrm{O}_{4}$ particles were added into the flask at different time under mechanical stirring. The final product was washed, dried at $-50{ }^{\circ} \mathrm{C}$ and conserved in the dryer.

The other ferromagnetic nanoparticle used in this study is the superfine iron (SI), which was provided by the Research Center for Nano Technology of the Chinese Iron and Steel Institute. Its physiochemical properties may be found in the Master's thesis of Chunfeng Hou (2009).

\subsection{Synthesis of PACl2.0 and of MPACl2.0s}

The PACl2.0 was prepared by slow base titration of $0.5 \mathrm{~mol} / \mathrm{L}$ $\mathrm{AlCl}_{3}$ solution with $0.2 \mathrm{~mol} / \mathrm{L} \mathrm{NaHCO}_{3}$ solution under rapid stirring to achieve the target molar $\mathrm{OH} / \mathrm{Al}$ ratio (basicity value) of 2.0 (Tang, 2006).

MPACl2.0s were synthesized by blending PACl2.0 with ferromagnetic nanoparticles on a shaking table at room temperature $\left(25^{\circ} \mathrm{C}\right)$ for $2 \mathrm{~h}$ with a speed of $250 \mathrm{rpm}$. The final composited MPACl2.0s were aged for $24 \mathrm{~h}$, and conserved at $4{ }^{\circ} \mathrm{C}$. FSCSPs, two loading concentrations of 50 and $100 \mathrm{mg} / \mathrm{L}$, were respectively added into PACl2.0 solutions. Hence the formed MPACl2.0s can be described as PACl2.0 + FSCSP $(50 \mathrm{mg} / \mathrm{L})$ and PACl2.0 + FSCSP (100 mg/L) respectively. Loading concentrations were determined by means of apparent dispersibility. It may be noted that FSCSP aggregated more easily than the SI. Therefore, in order to make the ferromagnetic nanoparticles fully distributed at the surface of PACl2.0, only $25 \mathrm{mg} / \mathrm{L}$ was chosen as the loading concentration of the SI (PACl2.0 + SI $(25 \mathrm{mg} / \mathrm{L}))$. 


\subsection{Characterization of the ferromagnetic nanoparticles, PACl2.0, and MPACl2.0s}

The particle size and morphology of FSCSP and SI were determined by transmission electron microscopy (TEM) (S-570, Hitachi, Japan). The surface charges of the two nanoparticles were analyzed with a zeta potential meter (Zetasizer, Malvern, UK) by adjusting the $\mathrm{pH}$ of their suspensions from 3 to 11 with 1.0 and $0.1 \mathrm{~mol} / \mathrm{L} \mathrm{NaOH}$ and $\mathrm{HCl}$ solutions. Moreover, zeta potentials of MPACl2.0s and PACl2.0 were also measured. The specific surface area and pore size distribution were measured by a Brunauer, Emmett, and Teller (BET) surface area analyzer (ASAP-2000, Micromeritics, US) for nitrogen adsorption. The BET method was carried out under relatively high vacuum and measured primarily the external area of the particles and aggregates.

$\mathrm{Al}$ species of MPACl2.0s and PACl2.0 were characterized by $500 \mathrm{MHz}{ }^{27} \mathrm{Al} \mathrm{NMR}$, and instrumental settings and experimental conditions were addressed elsewhere (Xu et al., 2003). The internal standard was $0.05 \mathrm{~mol} / \mathrm{L} \mathrm{NaAlO}_{2}$ with its chemical shift at $80 \mathrm{ppm}$ downfield. The signals near 0 and $62.5 \mathrm{ppm}$ represent mononuclear $\mathrm{Al}\left(\mathrm{Al}_{\mathrm{m}}\right)$ and $\mathrm{Al}_{13}$, respectively. $\mathrm{Al}_{\mathrm{un}}$ (the amount of undetectable species) was obtained by:

$\mathrm{Al}_{\text {un }}=\mathrm{Al}_{\mathrm{T}}-\mathrm{Al}_{\mathrm{m}}-\mathrm{Al}_{13}$

\subsection{Preparation of synthetic water}

A synthetic water was prepared by dissolving the HA and kaolin stock suspensions with $1 \mathrm{mmol} / \mathrm{L} \mathrm{NaNO}_{3}$ and $0.8 \mathrm{mmol} / \mathrm{L}$ $\mathrm{NaHCO}_{3}$ so that the ionic strength and alkalinity of the solution could be kept at $1.0 \mathrm{mmol} / \mathrm{L}$ and $80 \mathrm{mg} / \mathrm{L}$ respectively. The $\mathrm{pH}$ was adjusted to $7.00 \pm 0.02 \mathrm{using} 0.1 \mathrm{~mol} / \mathrm{L}, 0.01 \mathrm{~mol} / \mathrm{L} \mathrm{NaOH}$ or/ and $0.1 \mathrm{~mol} / \mathrm{L}, 0.01 \mathrm{~mol} / \mathrm{L} \mathrm{HCl}$. The synthetic water had average measured zeta potential, turbidity, $\mathrm{UV}_{254}$ and DOC values of $-21.4 \mathrm{mV}, 75.6 \mathrm{NTU}, 0.254 \mathrm{~cm}^{-1}$ and $2.318 \mathrm{mg} / \mathrm{L}$, respectively. All measurements were obtained at room temperature.

\subsection{Coagulation jar tests}

Jar tests were performed on a programmable jar test apparatus (Daiyuan Jar Test Instruments, China) to investigate the coagulation performance of MPACl2.0s within the dosage range of $0.02-0.20 \mathrm{mmol} / \mathrm{L}$ as $\mathrm{Al}$. Before dosing, the three kinds of MPACl2.0s were shaken well in order to disperse the composited systems as uniformly as possible. The jar-test procedure consisted of a $30 \mathrm{~s}$ premix (250 rpm), a $1 \mathrm{~min}$ rapid mix (200 rpm), a 15 min slow mix (30 rpm) and a $20 \mathrm{~min}$ settling period.

A small amount of sample was taken immediately to measure the zeta potential (Malvern, Zetasizer 2000, UK) after a $30 \mathrm{~s}$ rapid mix. After settling, the supernatants were analyzed by a TOC analyzer (TOC-Vcph, Shimadzu, Japan) and $\mathrm{UV}_{254}$ (UV-Vis 8500, Hitachi, Japan) after filtration through a $0.45 \mu \mathrm{m}$ membrane. The turbidity was measured by a turbidimeter (Hach 2100P Turbidimeter, USA).

\subsection{Floc characterization}

Flocs were immediately collected from beakers after the slow stirring phase of the jar test with great care to avoid unnecessary "breakage". Image observation was done under a low resolution of $1 \mu \mathrm{m}(10 \times$ objective) using an electromotive microscope (Axioskop 2 mot plus, Carl Zeiss Co., Germany).

To investigate and compare the growth, breakage and regrowth of flocs produced by MPACl2.0s and PACl2.0, experiments similar to those of Zhu et al. (2009) were carried out. Briefly, coagulation tests were performed under the optimal dosage of $0.08 \mathrm{mmol} / \mathrm{L}$ as $\mathrm{Al}$. After the slow stirring phase, flocs were suddenly exposed to a 1 min strong stirring of $400 \mathrm{rpm}$ for breakage, and then regrowth was undertaken at $40 \mathrm{rpm}$ for $15 \mathrm{~min}$. Dynamic floc size was monitored in the whole procedure using SALLS (Mastersizer 2000, Malvern, UK). Size measurements were taken every $40 \mathrm{~s}$.

The inter-particle bonds that hold aggregate flocs together are considered as the cohesive strength of the flocs. A size ratio method is used here with an index (strength factor) to express the strength of particle flocs, i.e.,

Strength Factor $=\frac{d_{2}}{d_{1}} \times 100 \%$

where $d_{1}$ and $d_{2}$ are the mean sizes of the flocs before and after the shear breakage, respectively. A higher value of the
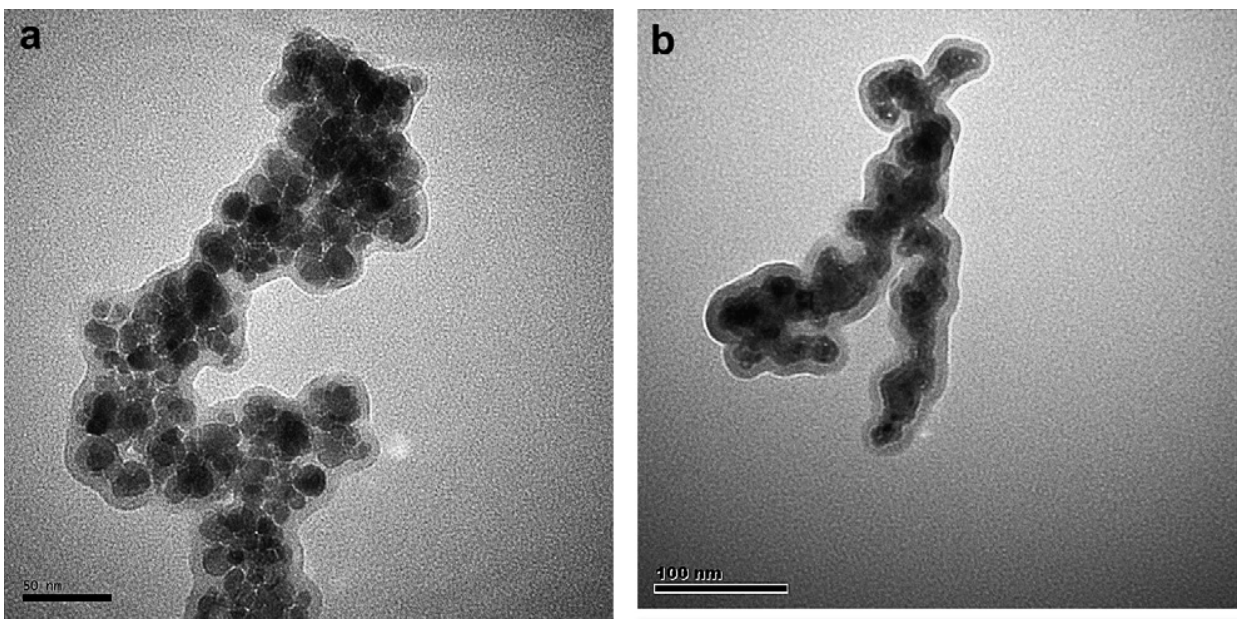

Fig. 1 - TEM images of two ferromagnetic nanoparticles: (a) FSCSP, (b) SI. 
strength factor indicates a higher ability of the flocs to resist breakage when exposed to an elevated fluid shear.

When the shear intensity was reduced after the breakage phase, re-flocculation of the particles could take place. A reversibility factor is used here to measure the reflocculation potential of the particles when the shear is returned to its original level. A modified size ratio approach may be applied to calculate the reversibility (Recovery Factor) by

Recovery Factor $=\frac{d_{3}-d_{2}}{d_{3}-d_{2}} \times 100 \%$

where $d_{3}$ is the mean size of the particle flocs after reflocculation at the original shear rate. A higher Recovery Factor suggests a greater flocculation and regrowth capability of the flocs after the shear breakage.

\section{Results and discussion}

\subsection{Properties of ferromagnetic nanomaterials}

\subsubsection{Size and morphologies of FSCSP and SI}

TEM images of FSCSP and SI are shown in Fig. 1. In Fig. 1(a), FSCSPs can be easily observed in the spherical shape with an average size of $20 \mathrm{~nm}$. The non-uniform-sized nanospheres form submicron aggregates with a visible $10 \mathrm{~nm}$ shell. The agglomeration is due to the magnetic dipole-dipole attraction and the large specific surface area of the magnetic particles (Liu et al., 2004), in spite of fierce stirring during the silica coating process. Fig. 1(b) confirms the core-shell structure of SI. The passivated layer is $\mathrm{Fe}_{3} \mathrm{O}_{4}$ according to the product description.

The TEM results reveal that the sizes of the ferromagnetic nanoparticles are of nanoscale before agglomeration. It has been reported that $\mathrm{Fe}_{3} \mathrm{O}_{4}$ is superparamagnetic if its diameter is around $16 \mathrm{~nm}$ (Hong, 2008). Unlike ordinary ferromagnetic particles, superparamagnetic materials have no hysteresis effect - once the external magnetic field is cut off, the remnant magnetism will disappear. This characteristic is favored the magnetic separation process since the magnetic sludge or flocs may be easily scraped when the magnetic field is off (Ngomsik et al., 2005).

\subsubsection{Specific surface area and pore volume}

Nanoparticles have been proven to have relatively large specific surface areas, leading to greater interface reaction rates (Li et al., 2006). The specific surface areas and pore diameters were $78.76 \mathrm{~m}^{2} / \mathrm{g}$ and $153.24 \mathrm{~A}$ for FSCSP and $22.51 \mathrm{~m}^{2} / \mathrm{g}$ and $63.48 \mathrm{~A}$ for SI respectively. They were determined by BET surface measurement. Apparently, compared with the commercially available SI, the lab-prepared FSCSP has a larger surface area with more sites to react with $\mathrm{Al}$ species or water pollutants.

\subsubsection{Surface electric charge}

The electric charge characteristics of both nanoparticles are shown in Fig. 2. Zeta potentials of FSCSP and SI decrease with increase in $\mathrm{pH}$ values, changing from $+18.7 \mathrm{mV}$ to $+26.0 \mathrm{mV}$ down to $-13.0 \mathrm{mV}$ and $-27.7 \mathrm{mV}$, respectively. The isoelectric

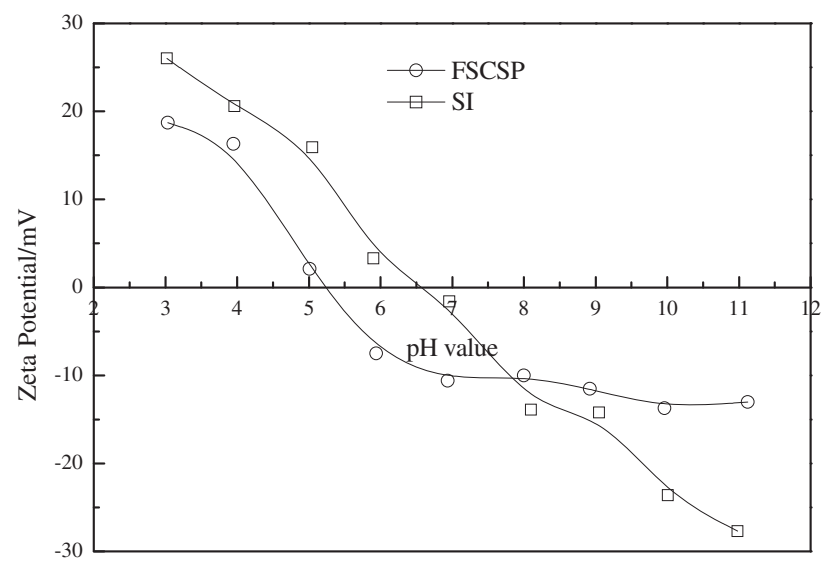

Fig. 2 - Variation of the zeta potentials of the ferromagnetic nanoparticles with $\mathrm{pH}$.

point (IEP) of FSCSP is at $\mathrm{pH} 5.2$ while that of SI is at pH 6.6. It is worth noting that magnetite can produce charges in the protonation and deprotonation reactions of $\equiv \mathrm{Fe}-\mathrm{OH}$ surface sites as expected for an amorphous solid (Hajdú et al., 2009). Therefore, both particles can be positively charged in composited coagulants since the $\mathrm{pH}$ value of PACl2.0 is around 4.02, lower than IEPs of SI and FSCSP (Table 1). Zeta potentials of the MPACl2.0s apparently rise with the addition of magnetic nanoparticles, and the $\mathrm{pH}$ values of PACl2.0 and MPACl2.0s are very close around 4.0 Among the three coagulants, PACl2.0 + FSCSP $(100 \mathrm{mg} / \mathrm{L})$ has a highest zeta potential of $21.5 \mathrm{mV}$ PACl2.0 + FSCSP $(50 \mathrm{mg} / \mathrm{L})$ has a lowest zeta potential. The zeta potential of PACl $2.0+\mathrm{SI}(25 \mathrm{mg} / \mathrm{L})$ is $20.5 \mathrm{mV}$.

\section{2. $\mathrm{Al}$ species distributions of $\mathrm{MPACl} 2.0$ s and $\mathrm{PACl} 2.0$}

All the coagulants were aged for 1 week. The liquid ${ }^{27} \mathrm{Al} \mathrm{NMR}$ method was used to characterize Al species distributions in MPACl2.0s and the original PACl2.0. The results are shown in Fig. 3. The $\mathrm{Al}_{\mathrm{m}}, \mathrm{Al}_{13}$ and $\mathrm{Al}_{\text {un }}$ contents of $\mathrm{PACl} 2.0$ were $12.8 \%$, $63.0 \%$ and $24.2 \%$, respectively. It should be noted that the $\mathrm{Al}_{\mathrm{m}}$ and $\mathrm{Al}_{13}$ contents decline whereas the $\mathrm{Al}_{\text {un }}$ content increases after compounding with ferromagnetic nanoparticles. Such change is more obvious for the two PACl2.0 + FSCSPs. When the loading concentration is $50 \mathrm{mg} /$ $\mathrm{L}, \mathrm{Al}_{\mathrm{m}}$ and $\mathrm{Al}_{13}$ contents decrease to $9.9 \%$ and $54.0 \%$, respectively. For $100 \mathrm{mg} / \mathrm{L}$, they further decrease to $9.3 \%$ and $52.5 \%$, respectively.

Table 1 - Characteristics of electric charges for PACl2.0 and MPACl2.0s.

\begin{tabular}{lcc} 
Types of coagulants & $\mathrm{pH}$ & $\begin{array}{c}\text { Zeta potential } \\
(\mathrm{mV})\end{array}$ \\
\hline PACl2.0 & 4.02 & 3.6 \\
PACl2.0 + FSCSP $(50 \mathrm{mg} / \mathrm{L})$ & 3.99 & 15.0 \\
PACl2 $20+$ FSCSP $(100 \mathrm{mg} / \mathrm{L})$ & 3.96 & 21.5 \\
PACl2 $20+$ SI $(25 \mathrm{mg} / \mathrm{L})$ & 3.95 & 20.5 \\
\hline
\end{tabular}




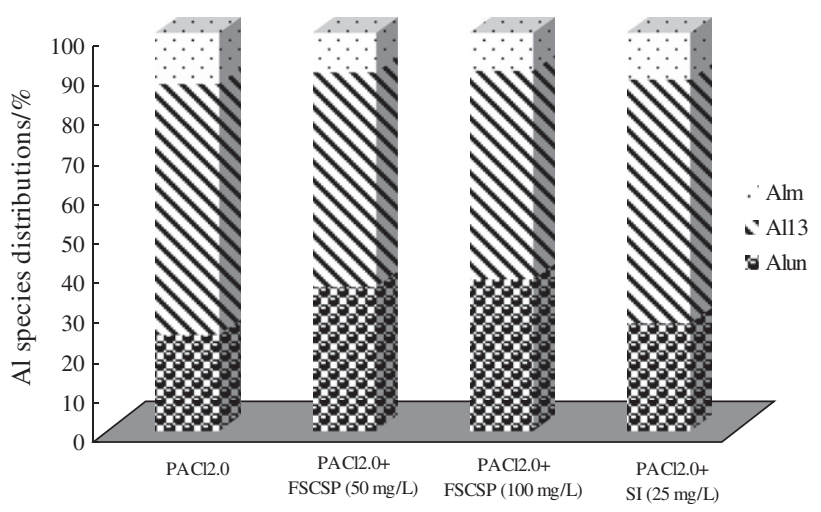

Fig. 3 - Comparison of $\mathrm{Al}$ species distributions.

All MPACl2.0s are in the form of solid-liquid mixure. The high surface energy, strong adsorption and magnetic attraction of nanoparticles are apt to play a significant role in their combination with $\mathrm{PACl} 2.0$. The high density of reactive surface sites and the great intrinsic reactivity of ferromagnetic nanoparticles will enhance the reactivity of the nanoscale particles (Li et al., 2006), and allow Al species to adsorb on their surface. In the process of compositing and aging the MPACl2.0, it seems that $\mathrm{Al}_{\mathrm{m}}$ and $\mathrm{Al}_{13}$ may firstly aggregate into $\left[\mathrm{Al}_{13}\right]_{\mathrm{n}}$ or $\left[\mathrm{Al}_{\mathrm{m}}\right]_{\mathrm{n}}$ on the surface ofthe nanoparticles, then transform to a sol or amorphous solid phase, and finally turn to other higher order aggregates. As a result, $\mathrm{Al}$ species-nanoparticle clusters form (shown in Fig. 7(a)), being identified as $\mathrm{Al}_{\text {un }}$. They are not only large in size and easy to precipitate but also have a crucial positive effect on bridging, enmeshment and sorption flocculation capacity.

MPACl2.0s with different nanoparticles and loadings lead to different $\mathrm{Al}$ species distributions. According to the BET results, FSCSP has a larger surface area and pore volume, offering more adsorption sites for $\mathrm{Al}$ species. Therefore, the content of $\mathrm{Al}$ species-nanoparticle clusters in PACl2.0 + FSCSP, in the presence of $\mathrm{Al}_{\mathrm{un}}$, will rise. As for MPACl2.0 with SI, since SI was more positively charged in PACl2.0 (Table 1), the electrostatic repulsion between $\mathrm{Al}$ species and SI particles may hinder their approach and aggregation, resulting in an inconspicuous increase of $\mathrm{Al}_{\mathrm{un}}$.

\subsection{Coagulation performances of MPACl2.0s and PACl2.0 with different dosages}

The HA and Kaolin particles removal efficiencies of MPACl2.0s and PACl2.0 and the zeta potential of the coagulated suspensions were comparatively investigated, as shown in Fig. 4.

As anticipated, the addition of the MPACl2.0s and PACl2.0 effectively reduced the surface charge of the particles in the synthetic water, resulting in particle destabilization (Fig. 4). As the dosage increased, the particle zeta potentials approached zero. Further increase in flocculant dose caused a certain extent of charge reversal of the particles. The isoelectric dosage (IED) of PACl2.0 + FSCSP (50 mg/L) is close to $0.0 \mathrm{mmo} / \mathrm{L}$ as $\mathrm{Al}$, slightly lower than that of the others which were higher than $0.10 \mathrm{mmol} / \mathrm{L}$ as $\mathrm{Al}$. The whole dosage range can be divided into three parts according to the change of zeta potentials and turbidity removals: (I) No significant flocculation from -30 to $-10 \mathrm{mV}$. Dosages of coagulants are too low for MPACl2.0s and PACl2.0 to effectively flocculate/coagulate with water pollutants. (II) Obvious flocculation from -10 to $0 \mathrm{mV}$. As the dosage increases, big flocs are formed and zeta potentials are close to the IEP. Optimal turbidity removals are achieved in this range. (III) Restability from 0 to $10 \mathrm{mV}$. In the high dosage range, the coagulation performance is ineffective.

The jar-test flocculation and sedimentation results for turbidity and DOC removals from the synthetic waters are in general agreement with the zeta potential analysis. For all four flocculants, it is obvious that the optimal dosage range for MPACl2.0s and PACl2.0 lies in Part II, and the optimal dosage is $0.08 \mathrm{mmol} / \mathrm{L}$ as Al. At the optimal dose, $90 \%$ of DOC and more than $90 \%$ of turbidity can be removed. Especially for PACl2.0 + FSCSP (50 mg/L), the DOC and turbidity removal efficiencies can reach $92 \%$ and $98 \%$, respectively. In comparison, $\mathrm{PACl}$ showed a slightly worse water treatment performance.

The results indicated that the nanoscale magnetic particles did play a significant role in DOC and particle removal. Firstly, ferromagnetic nanoparticles could affect the hydrolyzed $\mathrm{Al}$ species by increasing Al species-nanoparticle clusters, which may increase effective collision rates. Secondly, the addition of ferromagnetic nanoparticles would enhance the adsorption capability due to their large specific surface areas and magnetic dipole-dipole attraction, resulting in a higher removal rate of water pollutants (Li et al., 2006). Therefore,
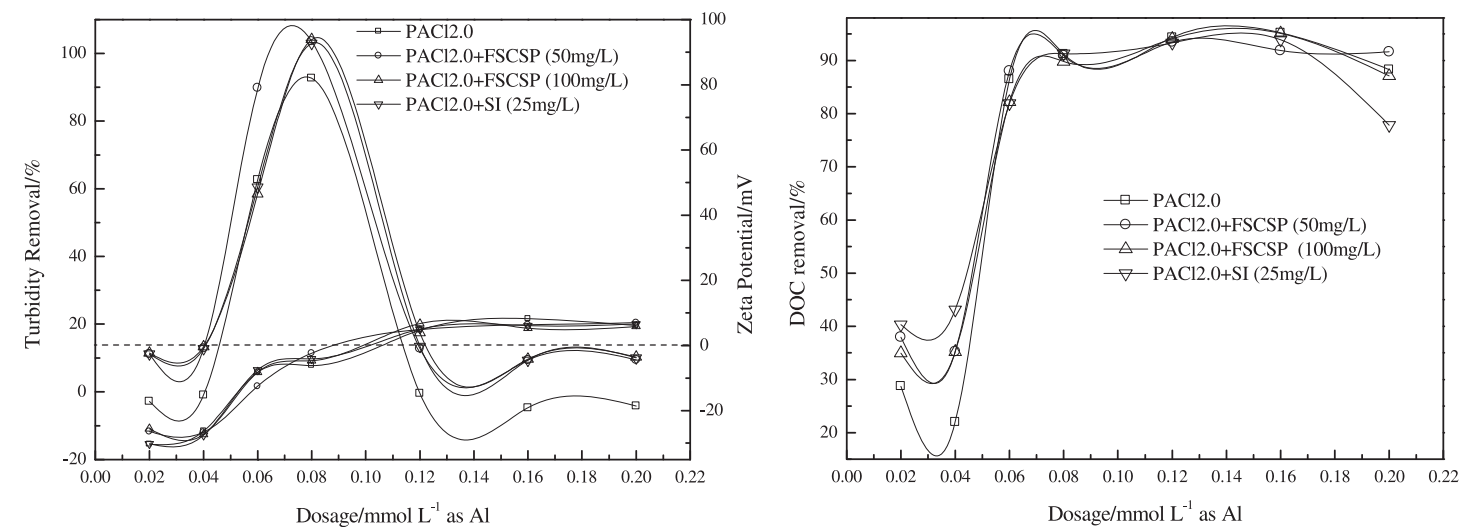

Fig. 4 - Variation of turbidity and DOC removal with coagulant dosages. 

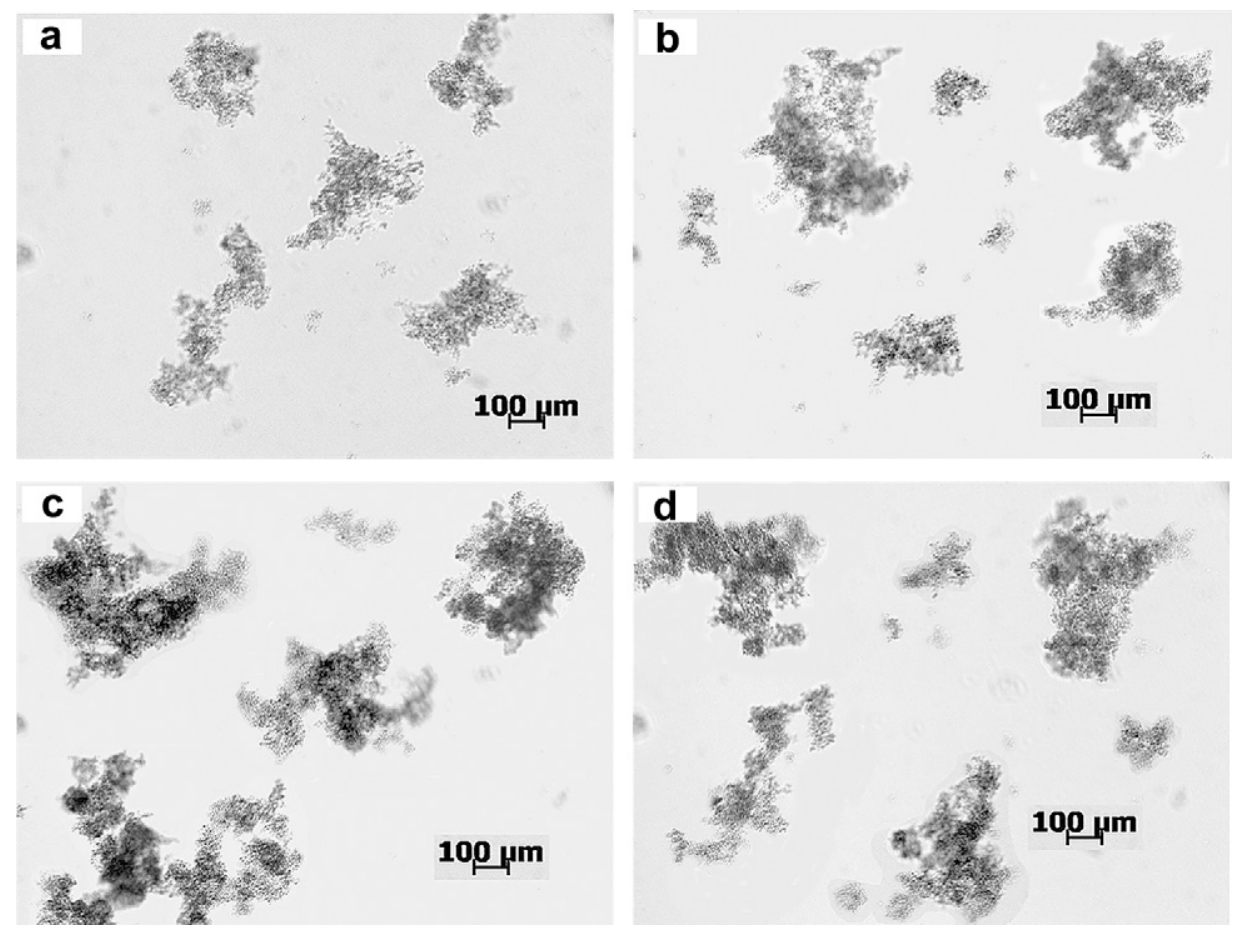

Fig. 5 - Representative images of flocs formed with (a) PACl2.0; (b) PACl2.0 + FSCSP (50 mg/L); (c) PACl2.0 + FSCSP (100 mg/L) and (d) PACl2.0 + SI (25 mg/L).

adsorption, enmeshment and sweep would have simultaneously taken place by adding MPACl2.0. That is the primary reason why the performance of $\mathrm{MPACl} 2.0$ coagulation is superior to that of PACl2.0 coagulation.

\subsection{Floc properties}

\subsubsection{Morphology of flocs}

Microscopic examination in this study (Fig. 5) suggested the formation of large and fractal-like flocs, resulting in the removal of turbidity and DOC in the suspension. Representative images of flocs coagulated by PACl2.0, PACl2.0 + FSCSP $(50 \mathrm{mg} / \mathrm{L}), \mathrm{PACl} 2.0+\mathrm{FSCSP}(100 \mathrm{mg} / \mathrm{L})$, and SI $(\mathrm{PACl} 2.0+\mathrm{SI}$ $(25 \mathrm{mg} / \mathrm{L})$ are shown in Fig. 5 . It may be noted the black dots were observed in the flocs formed by $\mathrm{MPACl}$, revealing that nanoscale magnetic particles were successfully composited with the PACl. This can also imply the formation of Al speciesnanoparticle clusters. Those clusters influence not only the kinetics of aggregation, but also the structure and resulting fractal dimension of the aggregates.

\subsubsection{Floc formation, breakage and regrowth}

The coagulation kinetics of PACl2.0 and MPACl2.0s are demonstrated in Fig. 6 . It shows the variation in the average floc size during the hydrodynamic sequencing. In the jar tests, all the four coagulants were dosed of $0.08 \mathrm{mmol} / \mathrm{L}$ as Al. After the slow mix phase, the coagulation for four suspensions achieved a steady-state with the mean sizes denoted as $d_{1}$ in Table 2. Then floc size was immediately reduced following an increase in shear. $1 \mathrm{~min}$ later, it can be assumed the flocs reached the size $d_{2}$. A reversibility phenomenon in terms of floc size was observed, as mentioned in previous studies (Yukselen and Gregory, 2002; Zhu et al., 2009). When the shear was reduced to its initial value, the broken particles could collide with each other again to form the larger ones. However, it may be noticed that the formed flocs could not regrow to anywhere near their previous size. This may be attributed to the different coagulation mechanisms. Flocs formed by charge neutralization should give total recoverability. Thus, the irreversible breakage of the flocs was considered as evidence that the flocs formed in these systems were not dominated by pure charge neutralization mechanisms and were therefore held together by chemical rather than physical bonds, such as the combination of entrapment

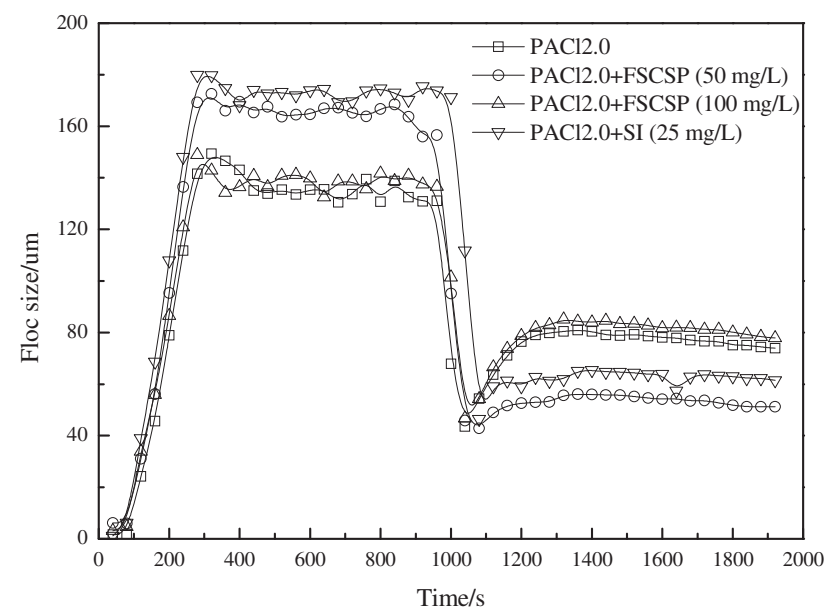

Fig. 6 - Comparison of the floc formation kinetics curves. 
Table 2 - Strength and recovery factors of MPACl2.0s and PACl2.0.

\begin{tabular}{lccccc} 
Suspensions & $\begin{array}{c}d_{1} \\
(\mu \mathrm{m})\end{array}$ & $\begin{array}{c}d_{2} \\
(\mu \mathrm{m})\end{array}$ & $\begin{array}{c}d_{3} \\
(\mu \mathrm{m})\end{array}$ & $\begin{array}{c}\text { Strength } \\
\text { factor }(\%)\end{array}$ & $\begin{array}{c}\text { Recovery } \\
\text { factor }(\%)\end{array}$ \\
\hline PACl2.0 & 136.5 & 43.6 & 73.9 & 31.9 & 32.6 \\
$\begin{array}{c}\text { PACl2.0 + FSCSP } \\
\quad(50 \mathrm{mg} / \mathrm{L})\end{array}$ & 165.4 & 42.9 & 51.3 & 25.9 & 6.9 \\
$\begin{array}{c}\text { PACl2.0 + FSCSP } \\
(100 \mathrm{mg} / \mathrm{L})\end{array}$ & 139.0 & 46.7 & 77.9 & 33.7 & 33.8 \\
$\begin{array}{c}\text { PACl2.0 + SI } \\
(25 \mathrm{mg} / \mathrm{L})\end{array}$ & 173.3 & 46.4 & 61.5 & 26.8 & 11.9 \\
\hline
\end{tabular}

bridging and complexation with coagulant metal hydrolysis species (Yukselen and Gregory, 2004).

Table 2 summarizes the values of the strength factor and recovery factor for the suspensions with different coagulants. $\mathrm{PACl} 2.0+\mathrm{SI}(25 \mathrm{mg} / \mathrm{L})$ and PACl2.0 + FSCSP (50 mg/L) are less able to resist the shearing condition, and their strength factor values are $26.8 \%$ and $25.9 \%$, respectively, lower than those of $33.7 \%$ for PACl2.0 + FSCSP (100 mg/L) and 31.9\% for PACl2.0. Meanwhile, recovery factors of PACl2.0 + SI $(25 \mathrm{mg} / \mathrm{L})$ and PACl2.0 + FSCSP (50 mg/L) are only as low as $6.9 \%$ and $11.9 \%$.

Compared with PACl2.0, the small addition of ferromagnetic nanoparticles slightly reduced the floc strength but severely weakened the recovery ability of the flocs. This can be explained according to the variation of the Al species shown in Fig. 3. The floc strength is dependent upon the interparticle bonds between the components of the aggregates. As reported by Wang et al. (2009), the $\mathrm{Al}_{\mathrm{m}}$ species can complex with $\mathrm{HA}$ to form large and strong flocs while the $\mathrm{Al}_{13}$ species react with $\mathrm{HA}$ to form small and unstable flocs. Those two HA-
Al flocs can be joined together by adsorption and bridging due to larger polymer and solid-phase $\mathrm{Al}(\mathrm{OH})_{3}$, resulting in larger flocs. In our study, the increase of $\mathrm{Al}_{\text {un }}$ in $\mathrm{MPACl} 2.0 \mathrm{~s}$, containing the probably existing $\mathrm{Al}$ species-nanoparticle clusters, may have helped to form larger flocs than PACl2.0. The decrease of $\mathrm{Al}_{\mathrm{m}}$ in MAPCl2.0s and the possible loose conformation of Al species-nanoparticle clusters may lead to weaker flocs.

Moreover, the results also indicate that flocs formed by MPACl2.0s show lower strength and reflocculating ability after breakage. As required for the magnetic particle recycling, the smash of magnetic flocs/sludge is a prerequisite, after which the separation of magnetic particles from the flocs/sludge is easier to achieve. Therefore, the incompact flocs, induced by PACl2.0 + FSCSP (50 mg/L) and PACl2.0 + SI (25 mg/L), are favored for practical purposes because of the low energy consumption for flocs/sludge breakage.

\subsection{Mechanisms of nanoscale magnetic coagulants}

The results of this work indicate that the ferromagnetic nanoparticles could play a significant role in coagulation. A plausible MPACl2.0 coagulation mechanism has been described schematically in Fig. 7. It can be noted that $\mathrm{Al}$ species-nanoparticle clusters will be formed when ferromagnetic nanoparticles are added into the PACl (as shown in Fig. 7(a)). The formed clusters would increase the proportion of $\mathrm{Al}_{\text {un }}$, which has a great potential to enhance charge neutralization, enmeshment and adsorption when aggregated with the pollutants. The flocs produced by those clusters exhibited different characteristics as shown in Fig. 4.

a
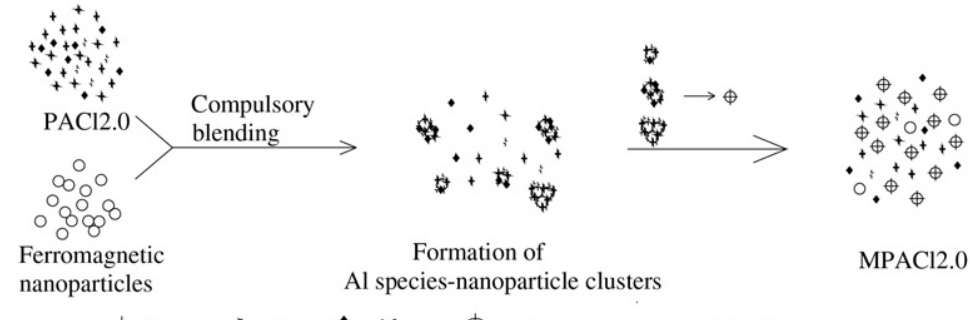

Formation of Al species-nanoparticle clusters

MPACl2.0

${ }_{7}^{\llcorner} \mathrm{Al}_{\mathrm{m}}+\mathrm{Al}_{13} \diamond \mathrm{Al}_{\text {un }} \oplus \mathrm{Al}$ species-nanoparticle cluster
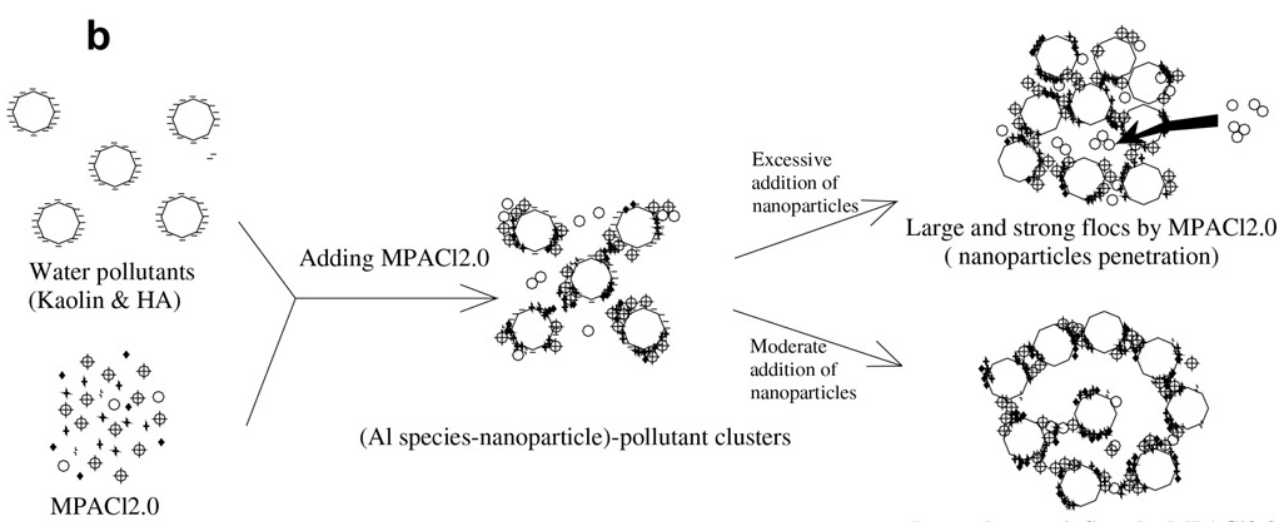

Larger but weak flocs by MPACl2.0

Fig. 7 - Coagulation mechanism of MPACl2.0: (a) formation of Al species-nanoparticle clusters in MPACl2.0, (b) coagulating process of MPACl2.0. 
As illustrated as Fig. 7(b), the flocs formed by PACl2.0 + FSCSP (50 mg/L) and PACl2.0 + SI (25 mg/L) are larger but weaker. As stated previously, ferromagnetic nanoparticles exhibited a preference to form Al species-nanoparticle clusters. These clusters enhance the bridge and adsorption effects, leading to a larger floc size. Moreover, the recovery factors of the flocs show marked differences. The recovery factors of PACl2.0 + FSCSP $(50 \mathrm{mg} / \mathrm{L})$ and PACl $2.0+\mathrm{SI}(25 \mathrm{mg} / \mathrm{L})$ are very low (6.9\% and $11.9 \%$ respectively). This implies that, in a suitable range of ferromagnetic nanoparticle addition, the connections between the clusters and pollutants are unique, being based on chemical bonds rather than physical ones.

Flocs formed by PACl2.0 + FSCSP (100 mg/L) showed a different situation. They were stronger and had a comparable size with those formed by $\mathrm{PACl}$. The difference is in the concentration of ferromagnetic nanoparticles. Apparently, PACl2.0 + FSCSP (100 mg/L) had the highest concentration. Aggregation of nanoparticles happened easily, and thus $\mathrm{Al}$ species-nanoparticle clusters were reduced. Therefore, the bridge and adsorption effects of $\mathrm{Al}_{\mathrm{un}}$ were limited to some degree, and the floc size did not obviously increase. Additionally, the formed flocs were considerably porous and fractal. The excess nanoparticles could penetrate into flocs. The embodiment of those nanoparticles would increase the strength of the flocs as indicated in Table 2.

\section{Conclusions}

Three novel ferromagnetic nanoparticle composites PACl2.0s (MPACl2.0s) were synthesized by compounding FSCSP and SI respectively with PACl2.0. They are described as PACl2.0 + FSCSP (50 mg/L), PACl2.0 + FSCSP (100 mg/L) and $\mathrm{PACl} 2.0+\mathrm{SI}(25 \mathrm{mg} / \mathrm{L})$. A series of characterizations in terms of physiochemical properties illustrated that the ferromagnetic nanoparticles used in the study were all core-shell particles with slight agglomeration and positive charge PACl2.0. FSCSP had a larger surface area and pore volume than SI did. All MPACl2.0s were in the form of solid-liquid mixing. Liquid ${ }^{27} \mathrm{Al}$ NMR measurements indicated that, compared with PACl2.0, $\mathrm{Al}_{\text {un }}$ content increased whereas $\mathrm{Al}_{13}$ and $\mathrm{Al}_{\mathrm{m}}$ declined with increase of ferromagnetic nanoparticle loadings. Al speciesnanoparticle clusters, attributed to $\mathrm{Al}_{\mathrm{un}}$, are suggested to form.

Coagulation jar tests revealed that the MPACl2.0s performed better than PACl2.0 in both turbidity removal, and DOC removal. Among the three MPACl2.0s, the coagulation behavior of PACl2.0 + FSCSP (50 mg/L) was the best. The improved coagulation efficiency of MPACl2.0s may be considered to be due to the co-effect of Al species, ferromagnetic nanoparticles and the possible $\mathrm{Al}$ species-nanoparticle clusters. Investigation of floc properties revealed that the key factor that influenced floc growth, re-flocculation, size and strength was the loading of ferromagnetic nanoparticles. Moderate nanoparticle loadings induced large but weak flocs that were hard to rearrange. Such flocs are favored for magnetic particle recovery.

The formation of $\mathrm{Al}$ species-nanoparticle clusters might have greatly contributed to the unique $\mathrm{Al}$ species distributions, the coagulation performance and the floc properties of
MPACl2.0. The additions of FSCSP and SI appeared to enhance the adsorption, enmeshment, and sweep abilities of MPACl2.0s, and to further strengthen the coagulated flocs by entering into the floc pores during flocculation. When the ferromagnetic nanoparticle loadings are controlled within a certain range, the connections between clusters and water pollutants were presumed to be chemical bonds since they had a considerably low recovery factors.

\section{Acknowledgments}

This research was funded by the Natural Science Foundation of China under 50921064, 51025830 and 51008293. The authors are very grateful to technical support from the Research Center for Eco-Environmental Sciences, Chinese Academy of Sciences.

\section{R E F E R E N C E S}

Ambashta, R.D., Sillanpää, M., 2010. Water purification using magnetic assistance: a review. Journal of Hazardous Materials 180, 38-49.

Hajdú, A., Illés, E., Tombácz, E., Borbáth, I., 2009. Surface charging, polyanionic coating and colloid stability of magnetite nanoparticles. Colloids and Surfaces A: Physicochemical and Engineering Aspects 347, 104-108.

Hong, R.Y., 2008. Preparation and Application of Magnetic Nanoparticles and Fluid, first ed. Chemical Industry Press, China. 11-12.

Hong, R.Y., Li, J.H., Zhang, S.Z., Li, H.Z., Zheng, Y., 2009. Preparation and characterization of silica-coated $\mathrm{Fe}_{3} \mathrm{O}_{4}$ nanoparticles used as precursor of ferrofluids. Applied Surface Science 255, 3485-3492.

Hou, C. F., 2009. The characterization of nanoscale-iron and synthetic resins and the test of their activity. MD thesis, Water Pollution Control Group of Municipal Engineering, Northern JiaoTong University, China.

Hu, C.Z., Liu, H.J., Qu, J.H., Wang, D.S., Ru, J., 2006. Coagulation behavior of aluminum salts in eutrophic water: significance of $\mathrm{Al}_{13}$ species and $\mathrm{pH}$ control. Environmental Science and Technology 40, 325-331.

Illés, E., Tombácz, E., 2006. The effect of humic acid adsorption on $\mathrm{pH}$-dependent surface charging and aggregation of magnetite nanoparticles. Journal of Colloid and Interface Science 295, $115-123$.

Jiang, C., Wang, R., Ma, W., 2010. The effect of magnetic nanoparticles on Microcystis aeruginosa removal by a composite coagulant. Colloids and Surfaces A: Physicochemical and Engineering Aspects 369, 260-267.

Johansson, G., 1960. On the crystal structures of some basic aluminum salts. Acta Chemica Scandinavica 14, 771-773.

Korbutowicz, M.K., Nowak, K.M., Winnicki, T., 2008. Water treatment using MIEX ${ }^{\circledR} \mathrm{DOC} /$ ultrafiltration process. Desalination 221, 338-344.

Li, L., Pan, M.H., Brown, R.C., Leeuwen, J.V., 2006. Synthesis, properties, and environmental applications of nanoscale ironbased materials: a review. Critical Reviews in Environmental Science and Technology 36, 405-431.

Li, Y.R., Wang, J., Zhao, Y., Luan, Z.K., 2010. Research on magnetic seeding flocculation for arsenic removal by superconducting magnetic separation. Separation and Purification Technology $73,264-270$. 
Liu, D., Cai, D.Q., Wang, X.Q., Yu, Z.L., 2006. Removal of algal blooms in freshwater by magnetic polymer. China Environmental Science 26 (6), 677-679.

Liu, Z.L., Wang, H.B., Lu, Q.H., Du, G.H., Peng, L., Du, Y.Q., Zhang, S.M., Yao, K.L., 2004. Synthesis and characterization of ultrafine well-dispersed magnetic nanoparticles. Journal of Magnetism and Magnetic Materials 283, 258-262.

Lu, Z.Y., Dai, J., Song, X.N., Wang, G., Yang, W.S., 2008. Facile synthesis of $\mathrm{Fe}_{3} \mathrm{O}_{4} / \mathrm{SiO}_{2}$ composite nanoparticles from primary silica particles. Colloids and Surfaces A: Physicochemical and Engineering Aspects 317, 450-456.

Ngomsik, A.F., Bee, A., Draye, M., Cote, G., Cabuil, V., 2005. Magnetic nano- and microparticles for metal removal and environmental applications: a review. Comptes Rendus Chimie 8, 963-970.

Odegaard, H., Fettig, J., Ratnaweera, H.C., 1990. Coagulation with prepolymerized metal salts. In: Hahn, H.H., Klute, R. (Eds.), Chemical Water and Wastewater Treatment. Springer-Verlag, New York, pp. 189-220.

Savage, N., Diallo, M.S., 2005. Nanomaterials and water purification: opportunities and challenges. Journal of Nanoparticle Research 7, 331-342.

Shen, Y.F., Tang, J., Nie, Z.H., Wang, Y.D., Ren, Y., Zuo, L., 2009. Preparation and application of magnetic $\mathrm{Fe}_{3} \mathrm{O}_{4}$ nanoparticles for wastewater purification. Separation and Purification Technology 68, 312-319.

Singer, P.C., Bilyk, K., 2002. Enhanced coagulation using a magnetic ion exchange resin. Water Research 36, 4009-4022.
Svoboda, J., Fujita, T., 2003. Recent developments in magnetic methods of material separation. Minerals Engineering 16, 785-792.

Tang, H.X. (Ed.), 2006. Inorganic Polymer Flocculation Theory and Flocculants, first ed. China Architecture and Building Press, China, pp. 11-12.

Van Benschoten, J.E., Edzwald, J.K., 1990. Chemical aspects of coagulation using aluminum salts - II. Coagulation of fulvic acid using alum and polyaluminum chloride. Water Research 24, 1527-1536.

Wang, Y., Gao, B.Y., Xu, X.M., Xu, W.Y., Xu, G.Y., 2009. Characterization of floc size, strength and structure in various aluminum coagulants treatment. Journal of Colloid and Interface Science 332, 354-359.

Xu, Y., Wang, D.S., Liu, H., Lu, Y.Q., Tang, H.X., 2003. Optimization of the separation and purification of $\mathrm{Al}_{13}$. Colloids and Surfaces A: Physicochemical and Engineering Aspects 231, 1-9.

Yukselen, M.A., Gregory, J., 2002. Breakage and re-formation of alum flocs. Environmental Engineering Science 19 (4), 229-236.

Yukselen, M.A., Gregory, J., 2004. The reversibility of floc breakage. International Journal of Mineral Processing 73, 251-259.

Zhang, R., Vigneswaran, S., Ngo, H., Nguyen, H., 2007. A submerged membrane hybrid system coupled with magnetic ion exchange $\left(\mathrm{MIEX}^{\circledR}\right)$ and flocculation in wastewater treatment. Desalination 216, 325-333.

Zhu, Z., Li, T., Lu, J.J., Wang, D.S., Yao, C.H., 2009. Characterization of kaolin flocs formed by polyacrylamide as flocculation aids. International Journal of Mineral Processing 91, 94-99. 